\title{
Aplikasi Sistem Informasi Geografis Produksi Padi dan Cabe di Kabupaten Lima Puluh Kota Berbasis Android
}

\author{
Harison ${ }^{1, *}$, Fuji Kurniawan ${ }^{2}$ \\ 1,2Program Studi Teknik Informatika Institut teknologi Padang \\ (corresponding author) harisonathar@gmail.com *
}

\begin{abstract}
West Sumatra is one producing areas of rice and chilli because geographical conditions favor, District Lima Puluh Kota is one of the production of rice and chilli. There are currently marketing products just drop it off at the nearest market, in terms of touch technology, crop farmers will be sought by marketing directly to the garden, because the need for rice and chilli is highly in the search market. Application geographic information system-based production of rice and chilli android designed using java programming language and database MySqLite and to take advantage of google maps GIS and immediately took the point coordinates at each Nagari or village that existed at Lima Puluh Kota.
\end{abstract}

Keywords - Rice; Chili; Geographic information system, Android.

\begin{abstract}
Intisari - Aplikasi Sistem informasi geografis produksi padi dan cabe berbasis android bertujuan untuk mendukung dan membantu permasalahan perdagangan komoditas padi dan cabe kabupaten Lima Puluh Kota merupakan salah satu daerah produksi padi dan cabe di sumatra barat. Saat ini pemasaran hasil produksi hanya di antarkan ke pasar terdekat, pada hal dengan sentuhan sistem informasi geografis maka hasil panen petani akan dicari oleh marketing ke kebun langsung, karna kebutuhan akan padi dan cabe ini sangat di cari pasar. Aplikasi Sistem informasi geografis produksi padi dan cabe berbasis android dirancang dengan menggunakan metode waterfaal, bahasa pemograman java dan database MySqLite dan untuk GIS memanfaatkan google maps dan langsung mengambil titik koordinat pada setiap Nagari atau Desa yang ada pada Kabupaten Limapuluh Kota. Hasil yang dicapai dalam pengujian aplikasi mampu memberikan data akurat terhadap daerah yang menghasilkan padi dan cabe di lima puluh kota.
\end{abstract}

Kata kunci - Padi; Cabe; Sistem informasi geografis; Android.

\section{PENDAHULUAN}

Produksi padi Sumatera Barat terus meningkat sejak dua tahun belakang pada tahun 2014 produksi padi 2.519 .020 ton tahun 2015, dan 2.550.609, untuk produksi cabe kriting pada dua tahun 2014, 59.321 ton dan 63.402 ton tahun 2015[1]. Kabupaten Lima Puluh Kota, salah satu kabupaten di sumatera barat mengacu pada data statistik. pada tahun produksi padi, 218.543 ton tahun 2012, 222.463 ton tahun 2013, 217.366 ton tahun 2014, tahun 2015 naik 227.184 ton. Produksi cabe keriting 3.238 ton tahun 2012, 3.349 ton tahun 2013, 3.520 ton tahun 2014, 4.273 ton tahun 2015 . [2]

Mayoritas pencaharian utama penduduknya adalah bermata pencaharian sebagai petani. Pada setiap wilayah Kabupaten Lima Puluh Kota banyak di kelilingi dengan lokasi pertanian terutama pada tanaman padi dan cabe kriting. Pada saat ini cara pemasaran dari padi dan cabe ini adalah dengan mengantarkan langsung ke pasar yang ada di kota payakumbuh yang akan didistribusikan ke konsumen di kota kota di sumatra barat dan juga kepada provinsi tetangga seperti riau jambi dan palembang dan untuk padi yang sudah digiling menjadi beras sering kali di distribusikan ke seluruh kota di sumatra dan juga pulau jawa, hal ini untuk memenuhi kebutuhan Rumah Makan Padang yang ciri khas nasi nya yang berderai. Untuk memudahkan pemasaran padi dan cabe pada waktu panennya di bangulah sebuah aplikasi sistem informasi geografis produksi mulai dari per Nagari atau Desa dan kecamatan. Dengan aplikasi ini dapat membantu membantu Dinas Pertanian dan para agen-agen yang ingin mencari lokasi produksi padi dan cabe kriting. kesulitan bagi para agen dan Dinas Pertanian, dalam mencari produksi padi dan cabe kriting yang banyak di setiap lokasi wilayah, di karenakan banyaknya lokasi tanaman pertanian yang terpencil membuat kesulitan dalam mendapatkan informasi tentang produksi padi dan cabe kriting.

Perkembangan Sistem Informasi Geografis sudah digunakan secara luas untuk mengakses informasi tentang suatu lokasi. Implementasi aplikasi android pencarian distribusi poin [3]. Pemetaan fasilitas umum di sumedan [4]. Aplikasi 
Game Android Pengenalan Pola Warna Pada Paud Posdaya untuk pendidikan anak usia dini yang bertujuan untuk mendeteksi buta warna dini pada anak anak [5]. Kuliner berbasis android menggunakan haversine formula [6], Pemanfaatkan teknologi Google maps yang merupakan layanan aplikasi online saat ini [7], Penyebaran dana bantuan operasional sekolah di rokan hilir [8]. Pemanfaatan penerapan Sistem informasi geografis merupakan langkah yang tepat untuk mengetahui informasi lokasi petanian yang terdapat di kabupaten lima puluh kota. Penerapan teknologi SIG dan android [8],[9], ke dalam aplikasi sistem informasi geografis produksi padi dan cabe untuk informasi tentang lokasi pertanian padi dan cabe kriting dapat di visualisasi ke dalam aplikasi android sehingga informasi tersebut dapat diakses secara umum tanpa ada batasan waktu dan tempat

\section{Metode Penelitian}

\section{A. Jenis Penelitian}

Jenis penelitian tugas akhir ini adalah membahas tentang perancangan aplikasi Sistem Informasi Geografis produksi padi dan cabe Kabupaten lima Puluh Kota. Sistem yang akan di rancang berbasis Android dimana data-data produksi penelitian ini berasal dari data Dinas Pertanian Kabupaten Lima Puluh Kota dan Dinas Pertanian Tanaman Pangan Provinsi Sumatera Barat. Pada penelitian ini juga dibatasi lokasi padi dan cabe kriting yang terdapat di wilayah Kabupaten Lima Puluh Kota.

\section{B. Lokasi penelitian}

Lokasi penelitian ini dilakukan di Kabupaten Lima Puluh Kota dan waktu penelitian direncanakan dari bulan Mei 2016 sampai Januari 2017.

\section{Alat dan Bahan}

Hardware dan software yang digunakan dalam penelitian ini adalah Perangkat Keras , Processor Intel(R) Core(TM) i32328M CPU @ 2.20GHz 2.20 GHz, Memori 4090MB RAM, Monitor Generic Pnp Monitor 1760 MB display 1366 x 768 32 bit $60 \mathrm{~Hz}$, VGA, USB, Smarphone Android untuk pengujian aplikasi yang akan dibuat minimal versi 5.1.1(Lolly Pop dan Software, Sistem Operasi Windows 7 Ultimete 32bit, Android Studio versi 1.4.1

Java Development Kit (JDK) versi 8u25 windows i586, SDK (Software Development Kit), untuk mengembangkan aplikasi pada platformAndroid dengan menggunakan bahasa pemrograman Java. JDK Java Developer'sKit.

\section{Teknik Pengumpulan Data}

Pengumpulan data dilakukan dengan tiga cara yaitu :

- Penelitian Kepustakaan (Library research)

Pengumpulan kepustakaan dilakukan dengan mengambil referensi yang berhubungan dengan tema penelitian untuk menyusun teori-teori yang berhubungan dengan pembahasan dari buku perancangan sistem, buku pemrograman, tugas akhir sebelumnya, badan pusat statistik dan beragam artikel dari internet.

- Wawancara

Wawancara dilakukan untuk mendapatkan informasi yang akurat sesuai dengan yang dibutuhkan dimana pengumpulan data dilakukan penelitian wawancara langsung dengan Dinas Pertanian Sumatera Barat dan para petani. Yakni dengan cara mengadakan tanya jawab langsung kepada pihak yang terkait, yang dapat memberikan penjelasan langsung ataupun data sebagai pelengkap penulisan ini.

- Pengamatan (Observasi)

Data yang didapatkan merupakan hasil dari pengamatan langsung ke lokasi lahan pertanian padi maupun cabe kriting.

\section{E. Context Diagram}

Context Diagram menggambarkan suatu sistem yang sedang berjalan secara keseluruhan[10], awal dan akhir dari data yang masuk dan keluar pada sistem tersebut. kejadian tersendiri dari aliran data dimana bagian utama atau fungsi yang diwakili oleh blok dihubungkan dengan garis yang menunjukkan hubungan dari blok. Secara garis besar perancangan sistem ini dapat digambarkan dalam bentuk konteks diagram berikut: 


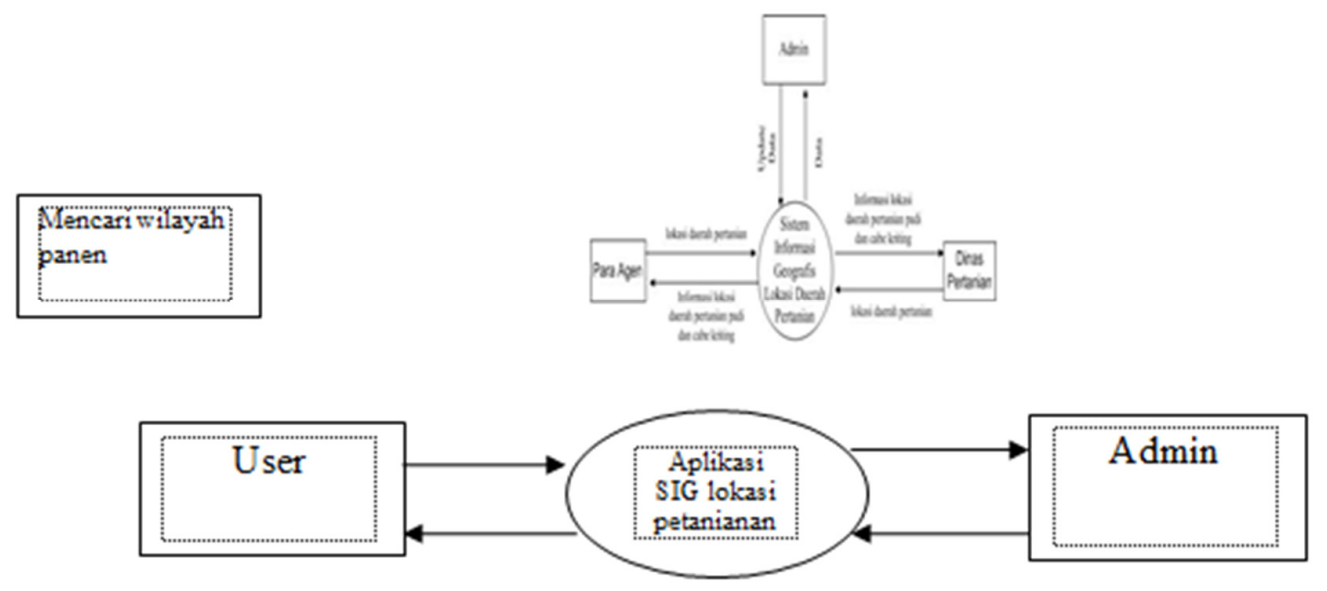

Gambar 1. Context Diagram

- Admin

Admin mengelola dan memperbaharui data-data pada sistem dan sistem memberikan informasi pemetan lokasi lahan pertanian tanaman padi dan cabe keriting kepada admin.

- Para Agen

Sistem memberikan informasi dan lokasi daerah pertanian padi dan cabe kriting kepada para agen.

- Dinas Pertanian

Sistem memberikan informasi dan lokasi daerah pertanian padi dan cabe kriting kepada dinas pertanian

\section{F. Entity Relationship Diagram}

Aplikasi ini terdiri dari 9 tabel yang saling berhubungan yaitunya tabel admin, cabe, cabe kota, titik koordinat kota, kecamatan, nagari, padi, padi kota, produksi.

\section{G. Merancang Antar Muka}

Perancangan terdiri dari 9 menu yang dimulai dari Splash Screen merupakan rancangan tampilan pada aplikasi saat aplikasi pertama kali dijalankan, user interface memudahkan pengguna dalam mengoperasikan aplikasi, menu produksi, menu Statistik, menu peta, menu bantuan, menu admin dan menu tentang aplikasi. Flowchart menu utama seperti gambar berikut [9] dan [10]. 


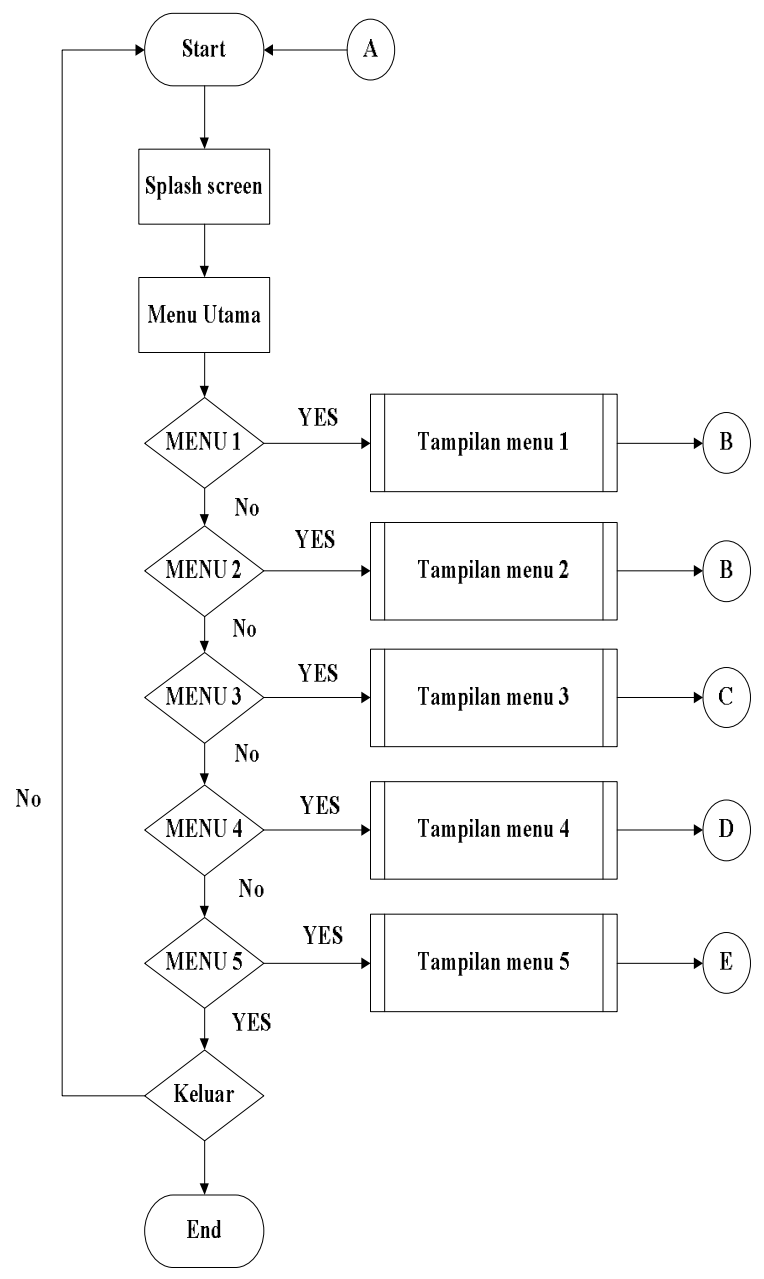

Gambar 2. Flowchart menu utama

III. Hasil PEnELITIAN

\section{A. Hasil Perancangan}

Hasil perancangan sistem informasi geografis produksi tanaman padi dan cabe pada kabupaten Lima puluh kota menghasilkan interaksi antara produsen dengan marketing serta juga peran dari pemerintah dalam mendata produksi tanaman padi dan cabe sangat di perlukan agar terkendalinya harga barang sampai kepada konsumen. Pada aplikasi ini user dapat melihat 6 menu yang tersedia, yang bisa dimanfaatkan untuk penelusuran Keterangan:

- Produksi, Tombol produksi akan menampilkan informasi jumlah produksi tanaman padi dan cabe kriting perTahun di Kabupaten Lima Puluh Kota.

- Statistik, Tombol statistik akan menampilkan informasi grafik tanaman padi dan cabe kriting di Kabupaten Lima Puluh Kota.

- About, Tombol About akan menampilkan informasi tentang manfaat penggunaan sistem dan pembuatan program.

- Peta, Tombol Peta akan menampilkan informasi tentang lokasi produksi tanaman padi yang ada di Kabupaten Lima Puluh Kota

- Bantuan, Tombol Bantuan akan menampilkan informasi tentang cara-cara menjalankan aplikasi agar pengguna mudah untuk menjalankannya.

- Keluar, Tombol Keluar berfungsi untuk keluar aplikasi. 


\section{B. Tampilan Menu Utama dan menu produksi}

User interface memudahkan pengguna dalam mengoperasikan aplikasi. Berikut menu utama dan produksi yang akan dibangun, dapat dilihat pada gambar berikut.

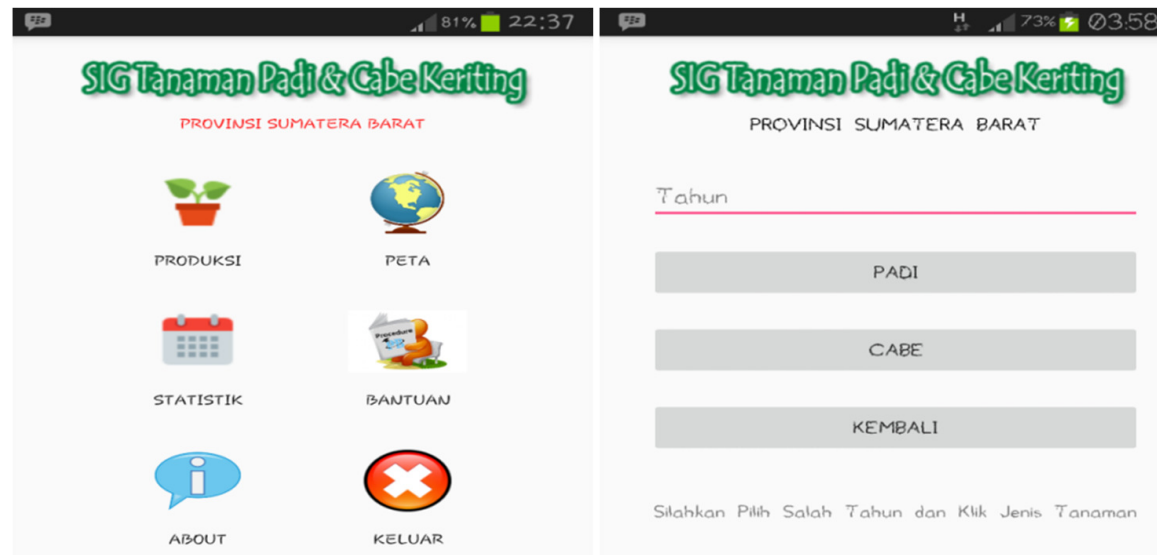

Gambar 3. Tampilan Menu Utama dan Produksi

- Tombol Padi akan menampilkan informasi tentang produksi tanaman padi di Kabupaten Lima Puluh Kota.

- Tombol Cabe akan menampilkan informasi tentang produksi tanaman cabe di Kabupaten Lima Puluh Kota.

- Tombol Kembali akan mengembalikan ke menu utama

\section{Tampilan Menu Statistik}

Pengguna, agen dan Dinas Pertanian harus memasukan tahun sebelum menjalankan sistem agar informasi hasil produksi padi dan cabe kriting disetiap wilayah di Kabupaten Lima Puluh Kota bisa di jalankan.

Tampilan antar muka daftar produksi padi dan cabe pada Tahun 2015, yang terdiri dari 13 Kecamatan Kabupaten Lima Puluh Kota gambar berikut.

\begin{tabular}{|c|c|c|c|c|c|c|c|c|c|}
\hline$\Delta$ & & & & $7.73: 0400$ & 둥 & & & & 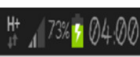 \\
\hline QAFTAR PROOL & $\mathbb{N} 2015$ & & & & QAFTAR PROQ & UN 2015 & & & \\
\hline KECAMATAN & $\begin{array}{l}\text { Tarom } \\
\text { (hal) }\end{array}$ & $\begin{array}{l}\text { Penen } \\
\text { (na) }\end{array}$ & $\begin{array}{l}\text { Proouks } \\
\text { (torn) }\end{array}$ & $\begin{array}{l}\text { Provitas } \\
(\text { toor/na) }\end{array}$ & KECAMATAN & $\begin{array}{l}\text { Tonam } \\
\text { (hat) }\end{array}$ & $\begin{array}{l}\text { Peren } \\
\text { (ha) }\end{array}$ & $\begin{array}{c}\text { Proodksi } \\
\text { (tor) }\end{array}$ & $\begin{array}{l}\text { Provitas } \\
(\text { ton } / \text { na })\end{array}$ \\
\hline Gunnng Omen & 277 & 2089 & 10335500 & 497 & Gunurg Qmen & 33 & 39 & 2988 & 7.66 \\
\hline Sulki & 2559 & 2382 & 1195330 & 5.02 & Sulki & 36 & 43 & 300.4 & 6.99 \\
\hline Buwt: Barisan & 4830 & 4570 & 2289760 & 4.99 & Bukt: Barisan & 114 & 132 & 1089 & 825 \\
\hline Gigaviok & 5119 & 5273 & 2570260 & 4.87 & Guguok & 46 & 39 & 2586 & 663 \\
\hline
\end{tabular}

Gambar 4. Tampilan Daftar Produksi Padi dan cabe 2015 
Pengguna, Agen dan Dinas Pertanian dapat melihat informasi diagram statistik perkembangan tanaman padi dan cabe kriting per-Tahun, halamannya dapat dilihat pada gambar berikut.

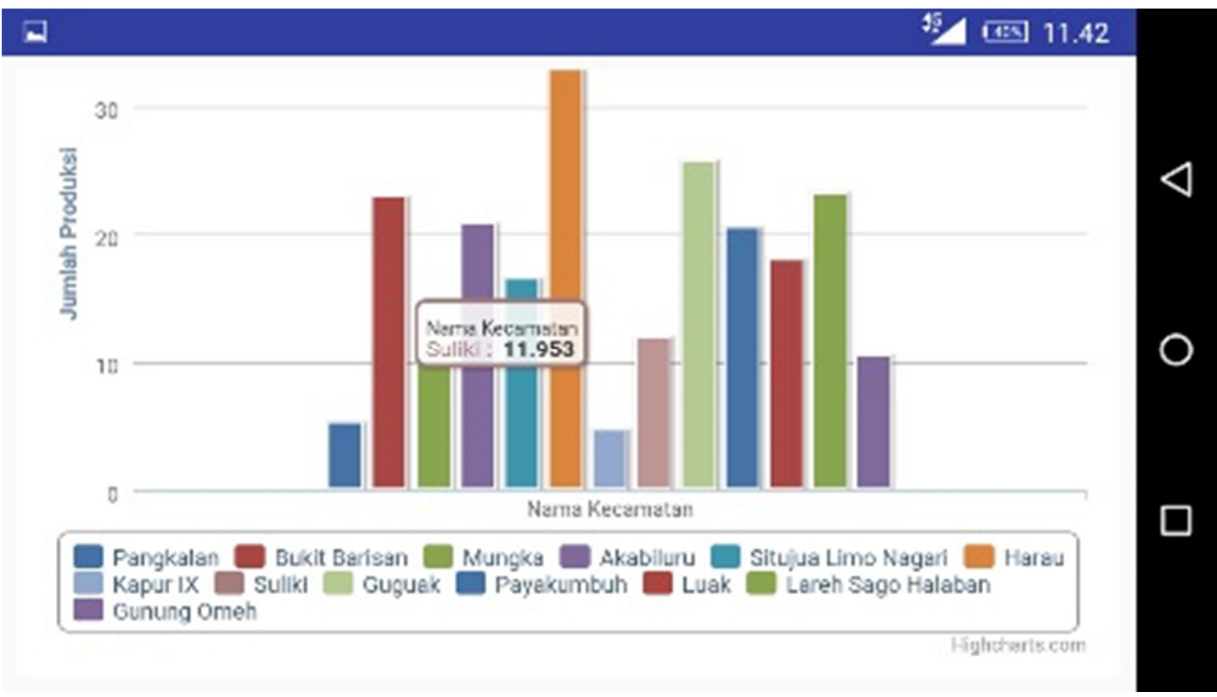

Gambar 5. Diagram Batang Produksi Padi dan Cabe Tahun 2015

\section{Tampilan Menu Peta}

Tampilan peta ini akan menampilkan lokasi tanaman padi dan cabe yang terdiri dari 12 kabupaten/kota di sumatra barat yang bisa menunjukan lokasi produksi dan jumlah produksi jika di tekan pada maker.. Berikut tampilan halamannya dapat dilihat pada gambar berikut.

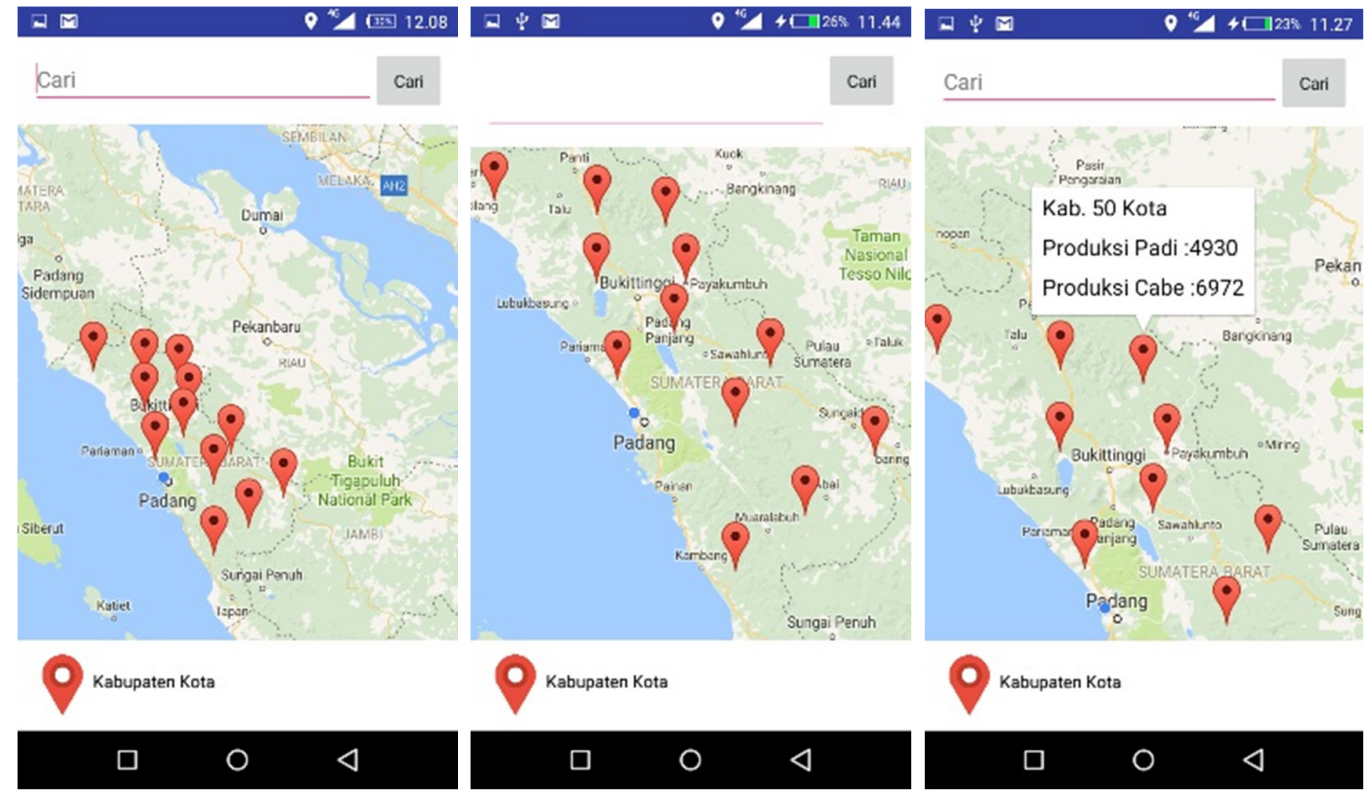

Gambar 6. Peta Produksi padi dan cabe Sumatera Barat dan 50 Kota

Pada Kabupaten Limapuluh Kota terdiri dari 13 kecamatan, dan 64 nagari, perancangan aplikasi ini di fokuskan di daerah lokasi Kabupaten Lima Puluh Kota. Untuk melihat lokasi kecamatan di Kabupaten Lima Puluh Kota pengguna, agen dan Dinas Pertanian terlebih dahulu mengklik marker di kab. 50 kota yang terdiri dari 13 kecamatan setelah maker limapuluh kota diklik akan keluar jumlah statistik produksi padi dan cabe dan sistem akan langsung mengubah tampilan 
dengan melihat tampilan Khusus produksi padi dan cabe pada Limapuluh Kota yang terdiri dari 13 kecamatan. Ketika mengkilik salah satu maker kecamatan maka juga keluar statistik produksi padi dan cabe dan sistem juga langsung menampilkan wilayah wilayah penghasil padi dan cebe di kecamatan tersebut. Kursor bisa kita tujukan pada setiap maker untuk melihat jumlah produksi. Berikut tampilan halamannya dapat dilihat pada gambar berikut.
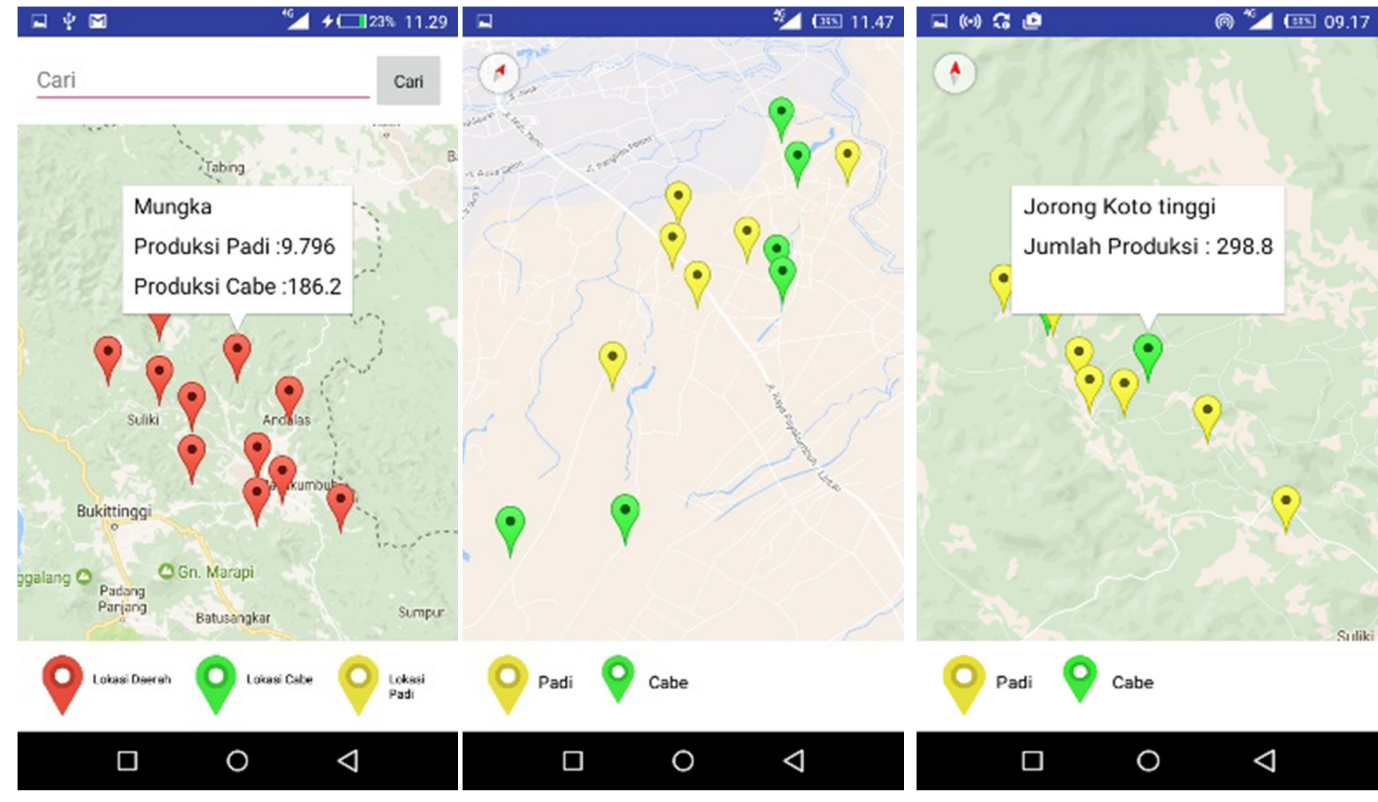

Gambar 7. Produksi padi dan cabe Khusus 50 Kota dan sebaran per Kecamatan

\section{E. Tampilan Menu Bantuan}

Menu bantuan akan menampilkan informasi tentang cara menggunakan sistem Informasi Geografis produksi padi dan cabe kriting, agar Pengguna, Agen dan Dinas Pertanian lebih mudah menjalankan sistem aplikasi ini. tampilan halamannya dapat dilihat pada gambar 8 .

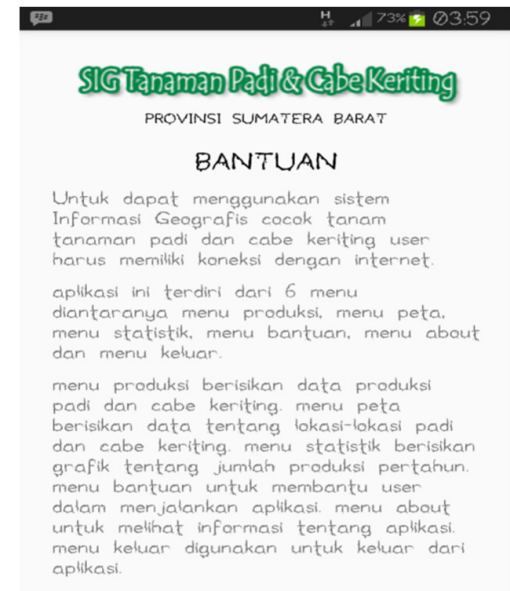

Gambar 8. Tampilan Menu Bantuan 


\section{KESIMPULAN}

Berdasarkan pengujian aplikasi sistem informasi geografis produksi padi dan cabe keriting Kabupaten Lima Puluh Kota berbasis android, ditujukan sebagai alat bantu untuk para agen atau marketing dan Dinas Pertanian dalam mengetahui lokasi dan informasi tentang produksi padi, para agen dan dinas pertanian mempunyai akses yang sama dimana hanya bisa melihat Informasi yang disediakan berupa info produksi tanaman padi dan cabe keriting yang produksinya paling tinggi di wilayah Sumatera Barat dan Kabupaten Lima Puluh Kota berserta navigasinya pada google map. Dimana lokasi yang ditampilkan disesuaikan dengan data lokasi yang terdapat pada server.

Aplikasi ini hanya bisa sempurna dijalankan dengan menggunakan smartphone android yang versi terbaru 5.0 .0 LollyPop. 2. Belum tersimpannya data dalam database perangkat user, jadi user harus selalu memuat data dari server. Hal ini akan berakibat pada saat user akan melihat data produksi padi dan cabe keriting pada saat tidak memiliki jaringan karena data tidak akan bisa dimuat. Maka dari itu penggunaan aplikasi ini selalu memerlukan jaringan untuk memuat data produksi padi dan cabe keriting yang ada.

\section{REFERENSI}

[1]. Panen Padi dan Cabe Kabupaten Lima Puluh Kota. https:// tanamanpangan_limapuluhkotakab.go.id

[2]. Pandhita. Ayu Laksmi. Implementasi aplikasi android pencarian distribusi poin. Jurnal infotel. Vol. No 7 November 2015

[3]. Bactiar. Adam Mukharil. Sistem informasi geografis pemetaan fasilitas umum di sumedan. Jurnal Komputer dan Informatika. Vol 1. No 2. Juli 2013.

[4]. Permana. Silvester Dian Handy Permana. Pembangunan Aplikasi Game Android Pengenalan Pola Warna Pada Paud Posdaya. Teknik Informatika.jurnal Infotel. Vol 7 No 2. November 2015.

[5]. Agustina. Dika. Sistem Informasi Geografis Kuliner Berbasis Android Menggunakan Haversine Formula Di Kota Yaogyakarta. digilib.uinsuka.ac.id. 2016.

[6]. Hamidi. Apliaksi Sistem Informasi Geografis berbasis Web Penyebaran Dana Bantuan OperasioanI Sekolah. Jurnal Masyarakat Informatika, Vol 2. No 3. 2011.

[7]. Toyibah. Mohammad Vieky. Sistem Informasi Geografis Pondok Pesantren di Kota Rembang Berbasis Android. eprints.dinus.ac.id. 2016.

[8]. Yuwono, Bambang. Sistem Informasi Geografis Berbasis Android Untuk Pariwisata Di Daerah Magelang. Jurnal telematika. Vol 12. No 2. 2015.

[9]. Huda, Arif Akbarul.24 JAM Pintar Pemograman Android. Jakarta. Andi Publisher. 2012.

[10]. Nugroho, Adi. Rekayasa Perangkat Lunak Menggunak UML dan Java. Yogyakarta: Andi. 2010. 